\title{
Application of the Concept of Terminal Value in the Analysis of Projects Based on Renewable Energy
}

\author{
Adriano Beluco', Alexandre Beluco², Carlos André Bulhões Mendes ${ }^{2}$ \\ ${ }^{1}$ Instituto Federal de Educação, Ciência e Tecnologia do Rio Grande do Sul (IFRS), Campus Viamão, Brazil \\ ${ }^{2}$ Instituto de Pesquisas Hidráulicas (IPH), Universidade Federal do Rio Grande do Sul (UFRGS), Porto Alegre, Brazil \\ Email: albeluco@iph.ufrgs.br
}

How to cite this paper: Beluco, A., Beluco, A. and Mendes, C.A.B. (2018) Application of the Concept of Terminal Value in the Analysis of Projects Based on Renewable Energy. Journal of Power and Energy Engineering, 6, 16-37.

https://doi.org/10.4236/jpee.2018.66002

Received: January 1, 2018

Accepted: June 17, 2018

Published: June 20, 2018

Copyright $\odot 2018$ by authors and Scientific Research Publishing Inc. This work is licensed under the Creative Commons Attribution International License (CC BY 4.0).

http://creativecommons.org/licenses/by/4.0/

\begin{abstract}
Projects for energy supply based on the exploitation of renewable energy have a very predictable cash flow. The initial costs are usually high, with the acquisition of technologically evolving equipment. However, maintenance costs are relatively low and easily predictable. Likewise, operating costs are often very low as there is no need to buy inputs. Power storage devices are often short-lived and contribute to a relative cost increase. At the same time, these projects are often not approved because they are directly compared to projects based on non-renewable resources, with cash flows that may not be so easily predictable and with much lower start-up costs. Fossil fuels have hardly predictable costs, established by non-technical criteria and related to geopolitical issues. In addition, their operating costs are usually very high, precisely because of the need to purchase fossil fuels. This paper proposes the calculation of terminal value in cash flows of power generation projects and its application for feasibility analysis of projects based on renewable resources. The proposed method suggests the calculation of terminal value as the moving average calculated for five-year intervals with constant growth rate of 5\%. This method also encourages the inclusion in the cash flow of annual values that add up to the end of the analysis period the sufficient value to renew the system components at the end of the usual analysis period of $20-25$ years. The application of the proposed method to a diesel wind system simulated with the well-known Homer software indicates the modification of the results of the Homer with the preference for systems with greater wind penetration instead of the systems with greater consumption of fossil fuels.
\end{abstract}

\section{Keywords}

Feasibility Analysis, Discounted Cash Flow Method, Terminal Value, 


\section{Introduction}

The process of implementing and developing infrastructure for power generation from renewable energy resources requires a set of measures involving financial resources, time and commitment. This process is based on decisions affected by political, business and technical factors, based on analytical methods of evaluation of investment projects.

One of the valuation methods considered to be economically sophisticated is known as Discounted Cash Flow (CDF) or Net Present Value (NPV). The discounted term is due to the discount rate used to project the expected cash flow for the life cycle of a project to its initial investment date, where each cash flow amount is brought to date zero. The denomination Net Present Value refers to the result of the sum of the already discounted cash flows. The discount rate is also portrayed as an opportunity cost rate of the investor, that is, the rate of return obtained from the choice for a particular investment.

The discounted cash flow method has been used by several researchers for the evaluation process of investments in energy projects. Lee and Shih [1] present a quantitative model of the evaluation of the effect of energy policies for the development of renewable technologies compared to the variability in the prices of fossil fuels. Akdag and Güler [2] use net present value to assess the costs involved in deploying wind power technologies in 14 locations in Turkey. Kaabeche et al. [3] present a techno-economic evaluation and optimization model of integrated photovoltaic and wind energy conversion systems. Such a model is based on concepts such as net present cost, total annual cost and the analysis of the level of investments. The model in question makes use of a case study designed to meet the energy demand of a residential development in Bouzaréah, Algeria.

Lee [4] uses the analysis by approaching real options for investments in high uncertainty technology in a theoretical model of wind energy. The proposed model investigates the feasibility of using a theoretical method and its subsequent empirical analysis to evaluate investments in renewable energies from the perspective of the real options. This study confirms the multiple correlation between the use of the theoretical model based on real options, the empirical analysis and the sensitivity analysis in the decision making process for investments in renewable energies.

Martinez-Ceseña and Mutale [5] elaborate a methodology based on the real options approach for the planning of energy generation projects. The study is illustrated from a theoretical hydroelectric power generation model and the results obtained were compared with a classical, discounted cash flow method. Boomsma et al. [6] analyze investments in renewable energy through the pers- 
pective of different support policies from the perspective of the real options approach. In this study, such an investment analysis approach is used to determine the life cycle of an investment project from renewable sources and to optimize the selection of projects in scenarios of specific regulatory policies.

Kumbaroglu and Madlener [7] evaluate energy investment options through economic optimization. The authors propose a hybrid techno-economic valuation model that makes use of two classical approaches, the discounted cash flow and the real options. The first is intended to identify investment alternatives and the second to simulate the uncertainties inherent in the market price of energy through the Monte Carlo method. The proposed model was tested in a case study in Germany. Wüstenhagen and Menichetti [8] investigate strategic selection forms for investments in renewable energies in order to analyze the investment selection process and the degree of influence of the energy regulatory policies. In this study, the authors suggest a policy segmentation based on the heterogeneity of the profile of the investors based on the relation between the perception of the risks and the returns and the constitution of the portfolios of investments.

Espinoza and Rojo [9] and Espinoza [10] use a valuation method approaching Decoupled Net Present Value (DNPV) to disassociate the value of the financial resource through the time of the risk inherent in the investment. For the validation of the method the authors use a theoretical project of photovoltaic solar energy and the comparison with the net present value of the project.

The increasing use of characteristics derived from the discounted cash flow method for the feasibility analysis of investment projects in renewable energy technologies is mainly due to the increase in the volume of investments on a global scale. However, for a concise analysis it is necessary to consider some aspects inherent to the implementation of energy projects such as socio-political and economic factors involved in decision-making, external costs to the implementation of energy projects, discount rate or minimum opportunity cost making it attractive to the investor, as well as the life cycle designed for investment.

Investments in power generation capacity in recent years have focused on wind and solar power sources. Since 2010, the values injected into renewable energy technologies have surpassed the $\$ 200$ billion level. However, there was a decrease of around $8 \%$ in 2015 in the investment of renewable energies by developed countries. Except for large-scale water investments, for the first time in the last decade the developed countries' investments in renewable energy have been surpassed by developing and emerging countries. The difference in the volume of investments is due to the growing demand for electricity from developing and emerging countries resulting from the investment to increase the power generation capacity [11].

The practical implementation of a project in the renewable energy sector is directly influenced by strategic economic and socio-political factors. Twidell and Weir [12] state that $75 \%$ of a project is determined by institutional and sociopolitical aspects, while $25 \%$ by technical aspects. Thus, it is important to emphasize 
the decision-making role of politicians, private investors and legislators in the practical implementation of a project in the renewable energy sector. In addition, the lack of energy infrastructure in developing countries is responsible for a poor national electricity grid and critical technical and economic support.

This paper presents the application of the terminal value concept, commonly used in valuation of companies and businesses based on a discounted cash flow method, to evaluate the feasibility of projects based on renewable resources. The application of this concept will allow to compare in a direct way and in a same basis of comparison both systems based on renewable resources and systems based on fossil fuels.

The concept of terminal value will be used to compose a financial value for an energy generation system. This financial value can be considered as a comparison value with other systems or even as a value for negotiation of this system under study. A market assessment may allow renewable energy systems to be considered as alternatives for investment of financial resources. Thus, even the smallest systems and even those most hardly feasible may be compared with commercially established alternatives.

This paper consists of four sections besides this introduction. The next section details the concept of terminal value and the following section discusses its application to projects based on renewable energy resources. The fourth section presents a method for using the terminal value in the analysis of projects. The fifth section shows the application of this method to a wind diesel hybrid system and the sixth section ends summarizing the final remarks.

\section{On the Concept of Perpetuity or Terminal Value}

The terminal value or perpetuity (or even continuous value or horizon value) in a cash flow is the present value at a future moment of all future cash flows, from a given moment, when a relatively stable rate of growth is expected. This concept allows establishing long-term projections, reducing risks that limit its validity. The forecast of results beyond a certain period is impracticable and exposes such projections to an uncertainty involved in the prediction of industrial and macroeconomic conditions beyond a few years.

Thus, the perpetuity or terminal value allows the inclusion of the value of the future cash flows that occur beyond a projection period of several years, satisfactorily mitigating many of the uncertainties of the valuation of these cash flows. Perpetuity is calculated according to a flow of future cash flows projected in the discounted cash flow analysis. For purposes of evaluating a company or a business, there are two methodologies used to calculate perpetuity, which are the terminal value method and the perpetuity growth method.

The terminal value method is a simpler method, much applied in evaluating companies for sale. After an initial, explicit period of two to five years, in which the annual amounts correspond to the gross sales obtained with the sale of energy less the costs of operation and maintenance and the costs of eventual 
replacements of system components, the terminal value will be the value of the last year of the explicit period. This terminal value can also be determined as an average of the years of the explicit period or as an average of projections for subsequent years.

Figure 1 shows a cash flow with an expenditure at the initial time and with positive entries in the later years. In this figure, CF signifies cash flow and the subscript indicates the corresponding year of the cash flow. The figure indicates an explicit period corresponding to the first five years and the terminal value determined from the sixth year and the following years. In the diagram of this figure, the terminal value is a constant value, which can be determined in several ways, depending on the type of company or business being studied.

The perpetuity growth method considers the terminal value with a growth rate over time, usually constant. The application of a growth rate can account for the growth of the energy supply, reflecting the growth of the population and the growth of the expectation for better quality of the energy supplied. The growth rate may not be constant and in this case a multi-stage terminal value will be required. The settlement rate may even be negative in some periods, when the business is being devalued, or definitively, when the business is being finalized.

Figure 2 also shows a cash flow with an expenditure at the initial time and with positive entries in the later years, with the difference from the previous figure that the terminal value shows a constant rate of growth. In this figure, CF signifies cash flow and the subscript indicates the corresponding year of the cash flow. The growth rate must be determined from market-related considerations in which this business is embedded.

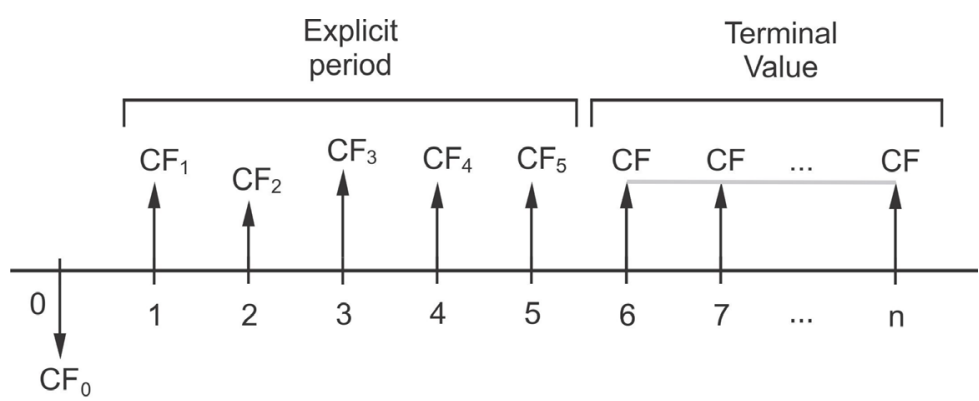

Figure 1. Cash flow presenting terminal value with constant rate.

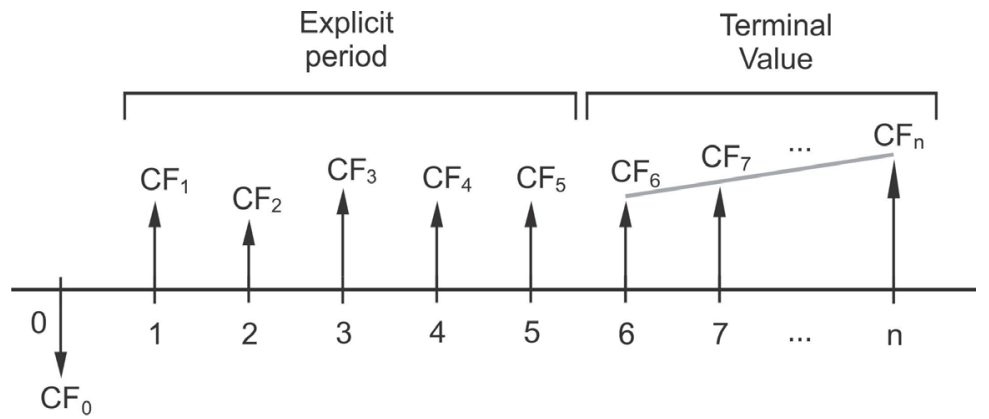

Figure 2. Cash flow with terminal value with increasing rate. 
Equation (1) shows the calculation of the net present value of the terminal value considering a constant rate throughout the future period. In this equation, TV [USD\$] is the terminal value, CF [USD\$] is the cash flow at time $n+1$, assumed to be the terminal value, and $i$ is the constant rate. This equation does not mention the method for determining the terminal value, which can be established according to the type of company or business under study.

$$
\mathrm{TV}=\frac{\mathrm{CF}}{i} .
$$

Equation (2) shows the calculation of the net present value of the terminal value for a constant rate of change. In this equation, CF [USD\$] is the cash flow and $g$ is the growth rate. While Equation (1) presents only one rate to be estimated, this equation presents two rates to be estimated and which can be sources of inaccuracies. Moreover, it is clear that a division by zero will occur if these two rates assume the same value.

$$
\mathrm{TV}=\frac{\mathrm{CF}}{(i-g)} .
$$

The explicit period, so-called because it is not included in the terminal period (which leads to the terminal value), includes the initial years of operation of the system. These initial years can be understood as a phase of adaptation of the users with the operation of the system and a phase of adaptation of behaviors. The terminal value is calculated from the sixth year onwards, considered the first year of the mature phase of system operation.

These two figures show cash flows limited to a sequence of $\mathrm{n}$ years. The total duration of the cash flow under study will depend on the type of company or business being analyzed. The duration will also depend on the accuracy in the projections for the years further away in the cash flow. However, depending on the type of system and the behavioral patterns of the people involved, the duration may even be several decades.

In a financial evaluation intending to assign value to a company or business, a valuation is obtained by the sum of two values, one associated with the explicit period and another with the terminal period. The total net present result will be obtained with the sum of the net annual results, obtained from the cash flow, of the explicit period after they have been brought to zero time by applying the discount rate.

Regarding the terminal period, first the general term of the terminal period is determined, to then reach the total value corresponding to perpetuity. The general term can be obtained in a few different ways, and the next section shows how to get this value by moving averages. Then, an infinite series of terminal values is brought by application of discount rate to time zero of the terminal period and finally summed. This value is then brought by a new application of the discount rate to the zero time of the analysis to constitute the terminal value.

Due to the characteristics of the cash flows, as discussed in the next section, 
the concept of terminal value can be conveniently applied in the feasibility analysis of power generation projects based on the exploitation of renewable energy resources.

\section{Application of the Terminal Value in the Analysis of Projects}

Projects for energy supply based on the exploitation of renewable energy have a very predictable cash flow. The initial costs are usually high, with the acquisition of technologically evolving equipment. However, maintenance costs are relatively low and easily predictable. Likewise, operating costs are often very low as there is no need to buy inputs. Power storage devices are often short-lived and contribute to a relative cost increase.

At the same time, these projects are often not approved because they are directly compared to projects based on non-renewable resources, with cash flows that may not be so easily predictable and with much lower start-up costs. Fossil fuels have hardly predictable costs, established by non-technical criteria and related to geopolitical issues. In addition, their operating costs are usually very high, precisely because of the need to purchase fossil fuels.

Figure 3 and Figure 4 show the cash flows for expenses, in a very simplified

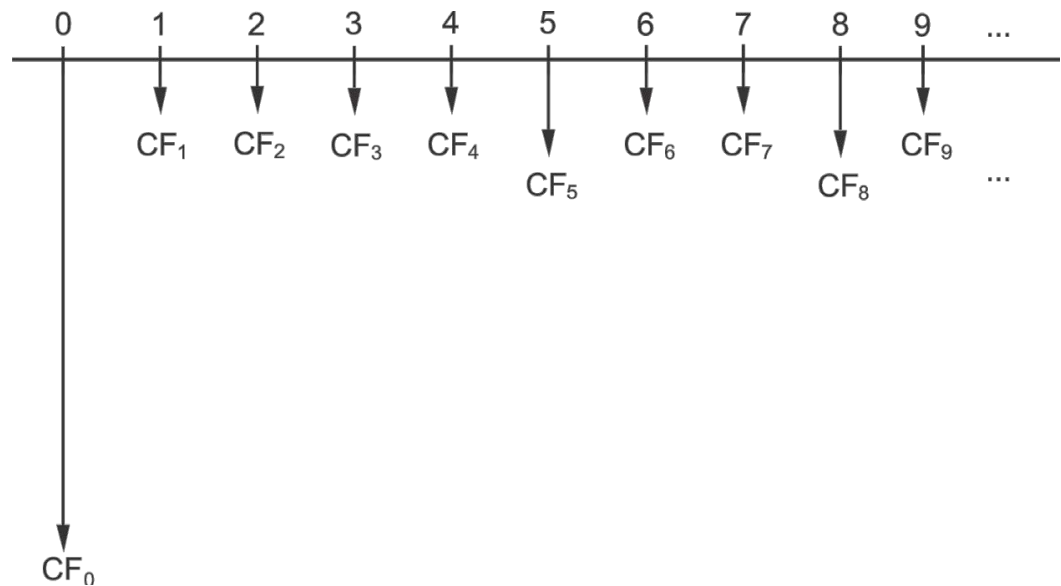

Figure 3. Typical cash flow from an energy generation system based on renewable resources.

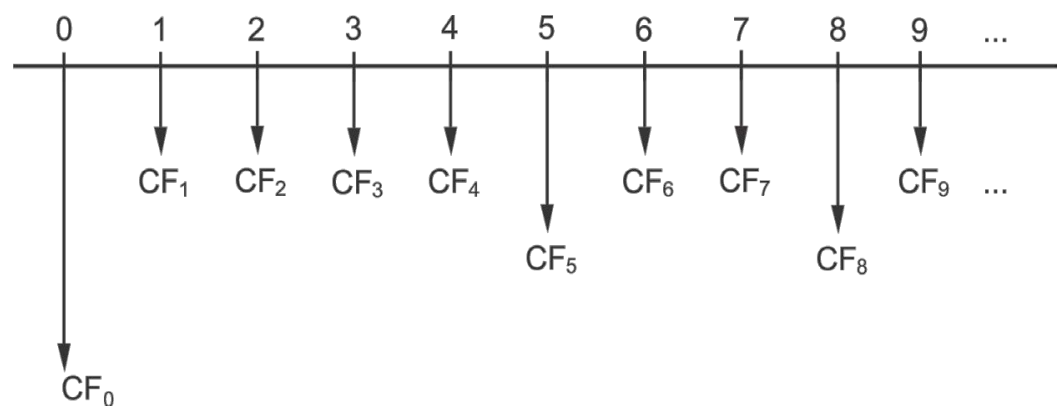

Figure 4. Typical cash flow from an energy system based on non renewable energy resources. 
way and mainly for a visualization of the values standards, respectively for systems based on renewable resources and for systems based on fossil fuels. The first value in Figure 3 corresponds to the higher initial costs of systems based on renewable resources. Likewise, the first value of Figure 4, usually much smaller, corresponds to the lower starting costs of fossil fuel-based systems.

In these figures, as in the previous figures, the annual values of the cash flow appear as $\mathrm{CF}$ and the subscript indicates the corresponding year. The value CF0 indicates the value corresponding to the zero time of the cash flow. These diagrams show the first nine years of cash flow and it is important to note that the analysis of systems based on renewable resources usually consider the useful life, most often 20 or 25 years.

Subsequent values in these two figures correspond to annual operating and maintenance costs, much lower in systems based on renewable resources and considerably higher in fossil fuel based systems. Some values that may be higher than the others (as in years 5 and 8 ) correspond to years in which any system component replacements are necessary. These differences between the two cost profiles obviously do not mean that the costs of fossil fuel-based systems are always lower.

The proposition of a method for evaluating the feasibility of power generation systems based on the terminal value analysis aims to propose an analysis tool that reduces the importance of the initial value and better values the annual costs of operation and maintenance. An analysis tool of this nature can contribute to a better comparison between systems with different cash flow profiles, also allowing the evaluation of renewable and non-renewable hybrid systems.

In addition, the terminal value can be estimated in projects with financial planning that allow the continuation of the project at the end of its useful life. The terminal value can be determined with annual inflows that allow the collection of an amount equal to the initial costs at the end of the useful life. Costs required for technological updating of system components and for repowering of energy conversion devices can be included.

The calculation of the terminal value also allows the extension of the cash flow beyond the time of analysis of 20 - 25 years usually adopted. In this way, the terminal value can be determined on the basis of longer projections since the inputs and the expenditures in this type of system can be predicted with better precision. As discussed in the following sections, this calculation can be performed based on moving averages.

The extension of the analysis time also allows the value to be charged for the energy supplied to the consumers (which will establish the annual input values and the possible profits obtained with the operation of the system) to include a value that allows the replacement of the equipment and components of the system. Thus, at the end of the usual analysis period, the system operator can have value equivalent to the initial investment available to ensure that the system will remain viable in the next cycle of operation. 
Concluding this reasoning, energy projects based on renewable resources are currently evaluated based on an analysis period of $20-25$ years. This period can be considered the explicit period, as shown in Figure 1 and Figure 2. Energy can be supplied to consumers at a price that allows a residual value at the end of the explicit period equal to the initial investment. In this way, the explicit period would then be evaluated by the net result of the period. The period after the explicit period would be evaluated by the terminal value.

A financial value can be attributed to the project based on the sum shown in Equation (3), as commented above. In this equation, $\mathrm{V}$ [USD\$] is the project valuation, NPR [USD\$] is the net present result obtained in the explicit period and TV [USD\$] is the terminal value. The valuation $\mathrm{V}$ of the project under study can be considered as a value that can be attributed to the project and can serve as a parameter for decision or as a parameter for financial comparison of this project when quoted with other projects, within certain limits, even if projects of different natures.

$$
\mathrm{V}=\mathrm{NPR}+\mathrm{TV} \text {. }
$$

A good parameter for project hierarchy can be obtained with the ratio between NPR and V, calculated considering NPR in absolute value. This parameter naturally indicates the importance of NPR in assessing the final value for $\mathrm{V}$ and will value systems with highest penetration of renewable energy. A system with higher diesel contribution will have higher operating costs and consequently a higher terminal value. Renewable energy systems will have lower terminal values.

Depending on the values assigned to the discount rate and the growth rate, the results may vary widely. These financial methods are heavily criticized because of this difficulty in predicting future cash flows. This ratio between NPR and V can be difficult to understand if NPR, or eventually NPR and V, present negative values. But the small variability of cash flows in power systems, especially those based on renewable resources, softens this unpredictability of future values.

Based on this discussion, the next section presents, in an objective way, a proposal for a method for applying the terminal value in the feasibility analysis of power generation systems.

\section{A Method for Analysis}

This section is composed of three subsections and the third one presents an analysis method for applying the terminal value in the feasibility analysis of projects for power generation. The first of these two subsections discusses how to calculate the terminal value as a moving average. The second subsection discusses the value to be adopted for the energy supplied to consumers and its consequence on the residual value at the end of the analysis period. The next section shows an application of this method to the feasibility analysis of a wind diesel hybrid system. 


\subsection{Calculating the Terminal Value as a Moving Average}

The method called moving averages is an alternative way of estimating a trend of a time series [13]. This method consists of calculating the arithmetic mean of the recent observations of the series under study [14]. For the estimation by moving averages, a stationary and locally constant time series, $L_{t}$, composed of its level, $\mu_{t}$, and a random noise, $\alpha_{t}$, as shown in Equation (4), should be considered. In this equation, $E\left(\alpha_{t}\right)=0, \operatorname{Var}\left(\alpha_{t}\right)=\delta_{\alpha}^{2}$ and $\mu_{t}$ is an unknown parameter varying with time.

$$
L_{t}=\mu_{t}+\alpha_{t}, t=1,2, \cdots, n
$$

The moving average takes the form shown in Equation (5), where $k$ determines the desired length of the moving average. Thus, $M_{t}$ is an estimate for the arithmetic mean of the $\mu_{t}$ level that disregards previous observations to the length of the moving average [14]. It should be noted that, with each new period, the oldest estimate is replaced by the most recent [13]. Thus, the forecast of the future values is given by the last estimated moving average, according to Equation (5).

$$
M_{t}=\frac{L_{t}+L_{t-1}+\cdots+L_{t-k+1}}{k}=M_{t-1}+\frac{L_{t}-L_{t-k}}{k} .
$$

In these equations, $L(s)$ is the forecast of the future values of the time series, defined in Equation (6). Second equation in Equation (6) corrects the estimate of $L_{t+s}$ with each new observation in the series, updating $L_{t+s}$ [14]. Assuming that the random noise $\alpha_{t} \sim N\left(0, \delta_{\alpha}^{2}\right)$, it is possible to state that $L_{t}(s) \sim N\left(\mu,\left(\delta_{\alpha}^{2}\right) / k\right)$, where a confidence interval with significance level $\alpha$ is obtained, represented by Equation (7), in which za is the quartile of a Normal distribution with significance level $\alpha$ [14].

$$
\begin{aligned}
& L_{t}(s)=M_{t} \\
& L_{t}(s)=L_{t-1}(s+1)+\frac{L_{t}-L_{t-k}}{k}, \quad \forall s>0 \\
& \quad\left(L_{t}(s)-z_{\alpha} \frac{\delta_{\alpha}}{\sqrt{k}}, L_{t}(s)+z_{\alpha} \frac{\delta_{\alpha}}{\sqrt{k}}\right) .
\end{aligned}
$$

The data presented in Table 1 show the cash flow obtained from the projection of the cash flow for the period of 25 years of analysis related to the simulation of a diesel wind hybrid system made with the well-known software HOMER. This data was obtained from the file Sample-Wind Diesel System.hmr [15], distributed along with the Legacy version of Homer [16]. The data presented in this table correspond to a wind speed of $4 \mathrm{~m} / \mathrm{s}$ and a diesel price of USD\$ 0.80 per liter.

In order to obtain the terminal value to be used as an annual term, the technique of moving averages for lengths of 5 years $(k=5), 10$ years $(k=10)$ and 15 years $(k=15)$ was applied, generally used in a practical way in the economic-financial market for the evaluation of investment projects in various industrial sectors. 
Table 1. Moving averages for 5, 10 and 15 years for the cash flow of the wind diesel hybrid system simulated with Homer software. Data available in Ref. [17].

\begin{tabular}{|c|c|c|c|c|}
\hline Period & Cash Flow & & ving avera & \\
\hline [years] & [USD\$] & 5 years & 10 years & 15 years \\
\hline 0 & $-99,900.00$ & & & \\
\hline 1 & $11,482.44$ & & & \\
\hline 2 & $11,482.44$ & & & \\
\hline 3 & $11,482.44$ & & & \\
\hline 4 & $11,482.44$ & & & \\
\hline 5 & -3517.56 & 8482.44 & & \\
\hline 6 & $11,482.44$ & 8482.44 & & \\
\hline 7 & $-12,517.56$ & 3682.44 & & \\
\hline 8 & $11,482.44$ & 3682.44 & & \\
\hline 9 & -3517.56 & 682.44 & & \\
\hline 10 & $11,482.44$ & 3682.44 & 6082.44 & \\
\hline 11 & $11,482.44$ & 3682.44 & 6082.44 & \\
\hline 12 & $-12,517.56$ & 3682.44 & 3682.44 & \\
\hline 13 & $-27,517.56$ & 4117.56 & 217.56 & \\
\hline 14 & $11,482.44$ & 1117.56 & 217.56 & \\
\hline 15 & $-11,017,56$ & 5617.56 & 967.56 & 2182.44 \\
\hline 16 & $11,482.44$ & 5617.56 & 967.56 & 2182.44 \\
\hline 17 & -3517.56 & 3817.56 & 67.56 & 1182.44 \\
\hline 18 & $11,482.44$ & 3982.44 & 67.56 & 1182.44 \\
\hline 19 & $-12,517.56$ & 817.56 & 967.56 & 417.56 \\
\hline 20 & $11,482.44$ & 3682.44 & 967.56 & 582.44 \\
\hline 21 & -3517.56 & 682.44 & 2467.56 & 417.56 \\
\hline 22 & $11,482.44$ & 3682.44 & 67.56 & 1182.44 \\
\hline 23 & $11,482.44$ & 3682.44 & 3832.44 & 1182.44 \\
\hline 24 & $-12,517.56$ & 3682.44 & 1432.44 & 582.44 \\
\hline \multirow[t]{2}{*}{25} & $41,821.44$ & 9750.24 & 6716.44 & 2605.44 \\
\hline & RMSE & 2181.76 & 2853.30 & 3704.23 \\
\hline
\end{tabular}

The term used to calculate the terminal value of a cash flow based on the moving averages technique is selected from the lowest Root Mean Square Error (RMSE) value. The estimated value is represented by the last moving average obtained. The results of Table 1 show that the 5-year length for moving average calculation is most appropriate.

Figure 5 shows the original data and the data obtained for the moving averages for these three calculation lengths. In this figure, it is possible to notice that there is no preponderantly increasing or decreasing behavior, ruling out the chance of adjustment by linear model. A good adherence of the calculated moving averages with 5 year length to the original data can be observed. 


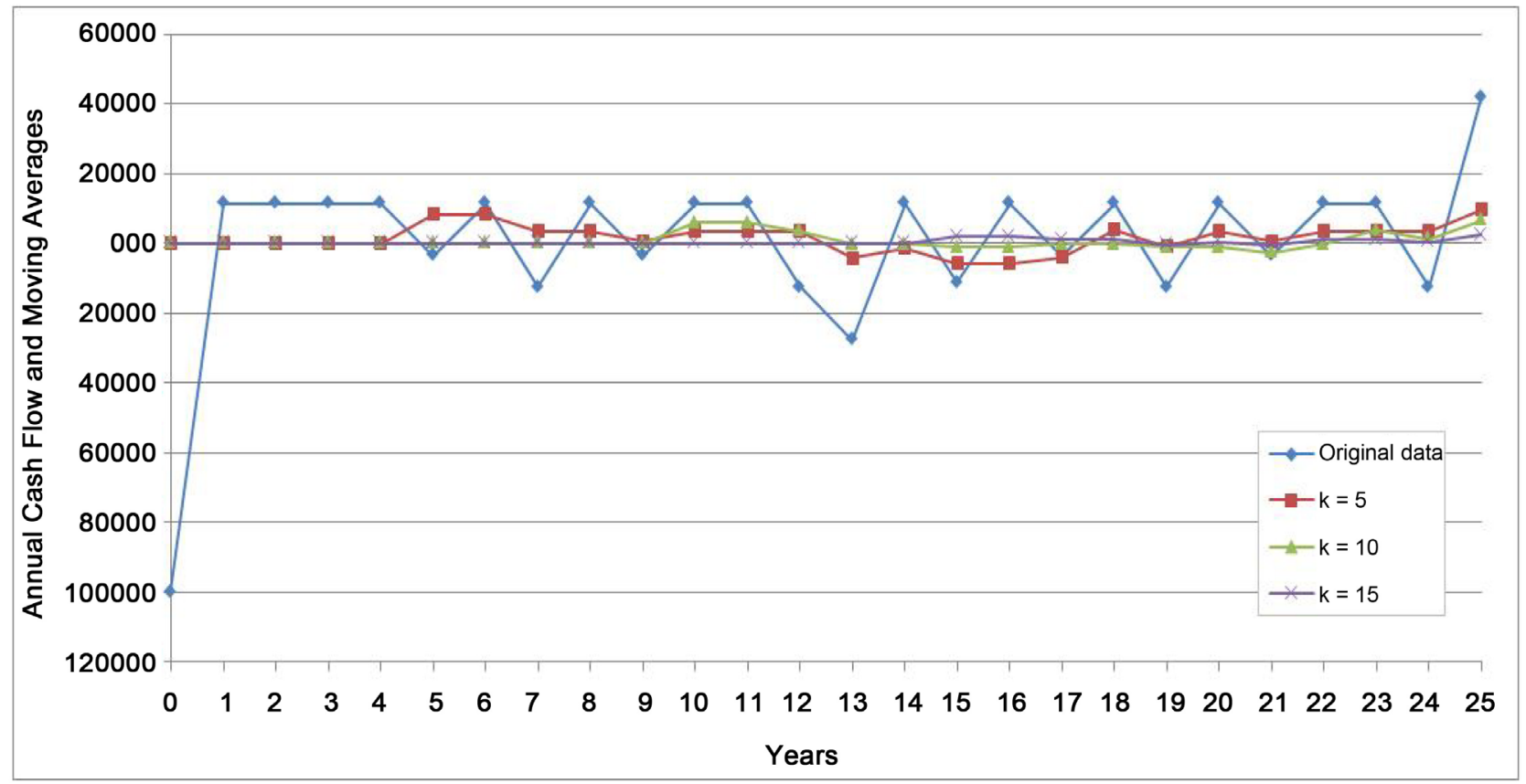

Figure 5. Annual cash flow data shown in Table 1 and terminal values calculated as moving average with lengths of 5 years $(k=$ $5), 10$ years $(\mathrm{k}=10)$ and 15 years $(\mathrm{k}=15)$.

\subsection{Residual Value at the End of the Analysis Period}

The second column of Table 1 shows a cash flow that has already been discussed in the previous subsection. This cash flow was obtained from the data of the file mentioned above, with a determined energy price so that there is no loss at the end of the 25 years of the analysis period. In this case, this available value at the end of the analysis period may be referred to as the residual value. In the case of the data in this table, a residual value equal to zero.

Another possibility considered in this study is that this residual value at the end of the analysis period of 25 years is made equal to the value of the initial investment corresponding to time zero. This decision would ensure that the financial continuity of the hybrid system was guaranteed at the end of the analysis period. This decision obviously raises the cost of the system over its operating period but at the same time raises its value as a business.

In other words, the energy price would be calculated to compensate for all costs over the period of analysis and still guarantee a residual value that will enable the continuation of the system for the next period. Or, on the other hand, this residual value could be understood as the payment for the initial investment, in this case without the inclusion of adjustments or updates. Thus, the balance of cash flows over the period of analysis will be sufficient for the continuity of the project.

The second column in Table 2 was obtained from the same data of the second column in Table 1, however the cash flows here were obtained for an energy price determined so that the residual value is equal to the initial investment. These data, as well as the previous ones, correspond to the case where the wind 
Table 2. Discounted cash flows for discount rates equal to $5 \%, 10 \%$ and $15 \%$ for the cash flow of the wind diesel hybrid system simulated with Homer software. Data available in Ref. [17].

\begin{tabular}{|c|c|c|c|c|}
\hline \multirow{2}{*}{$\begin{array}{l}\text { Period } \\
\text { [years] }\end{array}$} & \multirow{2}{*}{$\begin{array}{c}\text { Cash Flow } \\
\text { [USD\$] }\end{array}$} & \multicolumn{3}{|c|}{ Discounted cash flows } \\
\hline & & $5 \%$ & $10 \%$ & $15 \%$ \\
\hline 0 & $-99,900.00$ & $-99,900.00$ & $-99,900.00$ & $-99,900.00$ \\
\hline 1 & $15,478.44$ & $14,741.37$ & $14,071.31$ & $13,459.51$ \\
\hline 2 & $15,478.44$ & $14,039.40$ & $12,792.10$ & $11,703.92$ \\
\hline 3 & $15,478.44$ & $13,370.86$ & $11,629.18$ & $10,177.33$ \\
\hline 4 & $15,478.44$ & $12,734.15$ & $10,571.98$ & 8849.85 \\
\hline 5 & 478.44 & 374.87 & 297.07 & 237.87 \\
\hline 6 & $15,478.44$ & $11,550.25$ & 8737.18 & 6691.76 \\
\hline 7 & -8521.56 & -6056.11 & -4372.91 & -3203.57 \\
\hline 8 & $15,478.44$ & $10,476.42$ & 7220.81 & 5059.93 \\
\hline 9 & 478.44 & 308.41 & 202.91 & 136.00 \\
\hline 10 & $15,478.44$ & 9502.42 & 5967.61 & 3826.03 \\
\hline 11 & $15,478.44$ & 9049.92 & 5425.10 & 3326.99 \\
\hline 12 & -8521.56 & -4745.12 & -2715.23 & -1592.74 \\
\hline 13 & $-23,521.56$ & $-12,473.99$ & -6813.36 & -3822.91 \\
\hline 14 & $15,478.44$ & 7817.66 & 4075.96 & 2187.55 \\
\hline 15 & $-7021,56$ & -3377.49 & -1680.91 & -862.91 \\
\hline 16 & $15,478.44$ & 7090.85 & 3368.56 & 1654.10 \\
\hline 17 & 478.44 & 208.74 & 94.66 & 44.46 \\
\hline 18 & $15,478.44$ & 6431.61 & 2783.93 & 1250.74 \\
\hline 19 & -8521.56 & -3372.27 & -1393.34 & -598.77 \\
\hline 20 & $15,478.44$ & 5833.66 & 2300.77 & 945.74 \\
\hline 21 & 478.44 & 171.73 & 64.65 & 25.42 \\
\hline 22 & $15,478.44$ & 5291.30 & 1901.46 & 715.11 \\
\hline 23 & $15,478.44$ & 5039.34 & 1728.60 & 621.84 \\
\hline 24 & -8521.56 & -2642.26 & -865.16 & -297.69 \\
\hline \multirow[t]{2}{*}{25} & $45,817.44$ & $13,530.02$ & 4228.77 & 1391.83 \\
\hline & $99,900.00$ & $14,995.79$ & $-20,278.20$ & $-37,972.48$ \\
\hline
\end{tabular}

speed is $4 \mathrm{~m} / \mathrm{s}$ and the price of the oil is equal to USD $\$ 0.80$ per liter.

At the end of the analysis period (in this study considered equal to the explicit period), therefore, the financial resources for project continuity will be available. It is important to note that both this price for energy and the price determined so that the residual value is equal to zero are different from the cost of energy calculated by Homer. 
Neither type of return on investment was included in either of these two possibilities.

\subsection{Method of Analysis}

The method for applying the terminal value for feasibility analysis of renewable energy based energy systems has the following steps:

1) Establish the cash flow for the system under consideration, considering the initial costs for the acquisition of the system components, the annual operating and maintenance costs and the components replacement costs, according to their respective expected service life;

2) Calculate the amount to be charged for the energy supplied to consumers, considering two possibilities: (a) net final result equal to zero and (b) net final result equal to the value required for equipment acquisition and continuation of the system for the next analysis period;

3) Assume an explicit period of 20 - 25 years, equal to the period adopted in the usual feasibility analyzes and adopted for example by the well-known software Homer, assuming also that the terminal period starts from the subsequent year;

4) Determine the general term for the terminal value as the moving average calculated at intervals of five years, considering the last moving average as the general term for the terminal value, for evaluation criteria or for the valuation of the system under analysis;

5) Determine the value corresponding to the explicit period by bringing all the cash flows to time zero by applying the discount rate and then summing these values;

6) Determine the value corresponding to the terminal period by bringing all terminal values to the year after the end of the explicit period by applying discount rates and then summing these values, and finally bringing that sum to time zero by applying the corresponding discount rate ;

7) Determine the value adopted as the valuation of the energy system under analysis as an investment, adding the value corresponding to the explicit period with the value corresponding to the terminal period, brought to time zero by discount rates.

The proposed method does not consider the collection of amounts resulting in profit from the sale of energy supplied to consumers.

\section{Case Study: A Wind Diesel Hybrid System}

A case study presented as an attachment to the Legacy version of the well-known software Homer is considered in this work, for calculating the terminal value and subsequent interpretation of the results. This case study is the set of simulations present in the Sample-WindDieselSystem.hmr file. This section has three subsections: the first one describing the simulations performed with Homer, the second presenting the original results present in the file mentioned above and 
the third presenting the results of this work.

\subsection{Simulations with Homer}

HOMER (Hybrid Optimization Model for Electric Renewables) [16] is a software for optimization and sensitivity analysis of power generation systems [18] [19]. Homer is one of the most widely used software for hybrid systems design, allowing to design systems including photovoltaic modules, batteries, wind turbines, diesel generators, fuel cells, micro and small hydropower plants, hydrogen tanks, inverters, rectifiers and boilers, among others. Homer can be considered a modeling tool focused on the configuration of independent hybrid systems and hybrid systems connected to the power grid in emerging and developing countries.

The HOMER operating process is performed through three steps: simulation, optimization and sensitivity analysis. In the simulation stage, Homer models the performance of the specified configuration for power generation to determine the total cost for the project lifespan [18]. This step serves two purposes: to determine the feasibility of the generation system under study configured from the lowest total net present cost; and to estimate the cost of implementing and operating the investment project during its life cycle. The software simulates the operation of the proposed generation system configuration for the first year of operation to generate fuel consumption data, battery charge states, and so on. The economic and financial data obtained in the simulation are projected for the subsequent years of the project life cycle, disregarding eventual changes such as losses in equipment performance. Such changes can be explored in the sensitivity analysis step.

During the optimization stage, Homer simulates the generation system for all combinations of optimization variables. In this way, the optimal configurations are established following the criterion of the lowest total NPC. In the sensitivity analysis step, the simulations of the optimization step are still repeated, generating an optimal configuration for each combination of values of the sensitivity variables. Homer provides detailed data of all simulations, but the most striking result is the optimization space, which synthesizes optimal solutions for the combination of selected sensitivity variables. The direct results of the simulations carried out by Homer can be spelled out in the optimization space with a small symbol; the other results are obtained by interpolation, allowing the construction of a continuous surface and indicating the optimal configurations according to the values of the selected sensitivity variables.

The case study considered in this work consists of a wind diesel hybrid system and the file accompanies the Legacy version of software Homer, distributed free of charge by the company HomerEnergy. Figure 6 shows the system configuration on the left and the optimization variables in the table on the right. The system consists of wind turbines of type AOC 15/50 [20], by two diesel generators, one with $75 \mathrm{~kW}$ and the other with $150 \mathrm{~kW}$, by a bank of batteries of type 


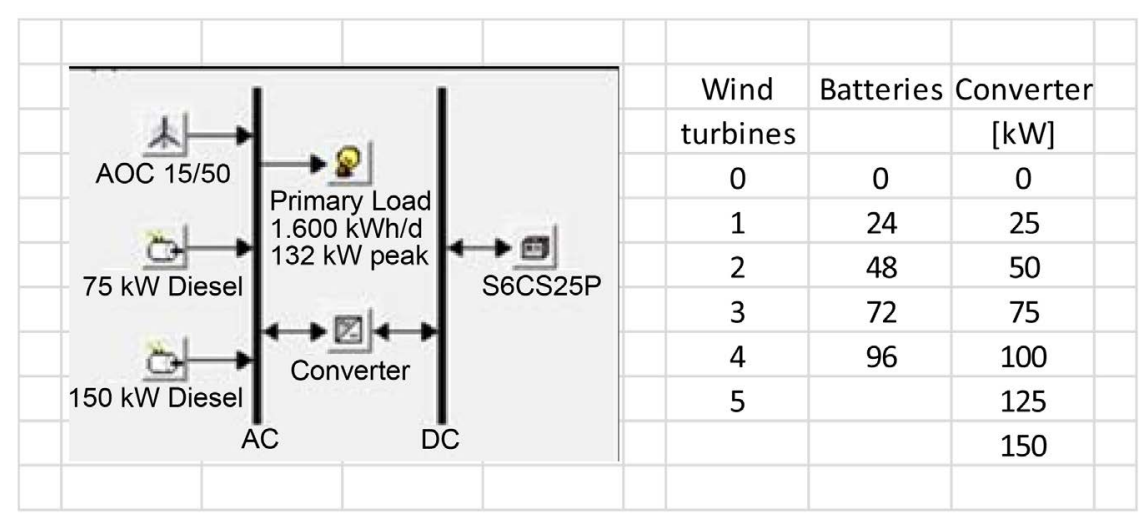

Figure 6. Schematic diagram of the wind diesel hybrid system under study and optimization variables considered in the simulations with Homer.

S6CS25P [21] and by a converter acting as an inverter and as a rectifier. This system must supply a load with daily consumption of $1600 \mathrm{kWh}$ per day with consumption peaks of $132 \mathrm{~kW}$.

Simulations were performed for the following values for the optimization variables: $0,1,2,3,4$ and 5 wind turbines; $0,24,48,72$ and 96 batteries; $0 \mathrm{~kW}$, $25 \mathrm{~kW}, 50 \mathrm{~kW}, 75 \mathrm{~kW}, 100 \mathrm{~kW}, 125 \mathrm{~kW}$ and $150 \mathrm{~kW}$ for the converter capacity. Simulations were performed for the following values for the sensitivity inputs: 4 $\mathrm{m} / \mathrm{s}, 5 \mathrm{~m} / \mathrm{s}, 6 \mathrm{~m} / \mathrm{s}, 7 \mathrm{~m} / \mathrm{s}$ and $8 \mathrm{~m} / \mathrm{s}$ for the scaled annual average wind velocity; USD \$ 0.20, USD\$ 0.40 , USD\$ 0.60 and USD\$ 0.80 per liter of diesel. A set of 210 simulations, with 20 different values for the sensitivity variables were performed. The results are presented and discussed in the next section.

\subsection{Results with Homer Based on Total Net Present Cost Criterion}

The most notable result provided by Homer appears in Figure 7, called the optimization space. This chart shows the optimal combinations of system components for each pair of wind speed and oil price values. The twenty values marked with a small white diamond correspond to the values effectively calculated by Homer, the other values being obtained by interpolation.

The optimal combinations correspond to combinations of system components resulting in lower total NPC value among all combinations calculated by Homer. Each point on the continuous surface shown in the chart of Figure 7 (part in dark blue, part in yellow and part in dashed yellow) corresponds to a different system and not to different states of the same system.

The system in Figure 6 leads to four possibilities: only the two generators (D75/D150), the two generators and batteries (D75/D150/Battery), the two generators and wind turbines (Wind/D75/D150) and the two generators, wind turbines and batteries (Wind/D75/D150/Battery). The chart in Figure 7 shows only three of these combinations, namely the first, third and fourth.

In this figure, the curve line dividing the areas in blue and yellow is a characteristic of wind diesel systems. The graph indicates that subject systems and lower wind speeds and lower oil prices will be better served by systems composed only 


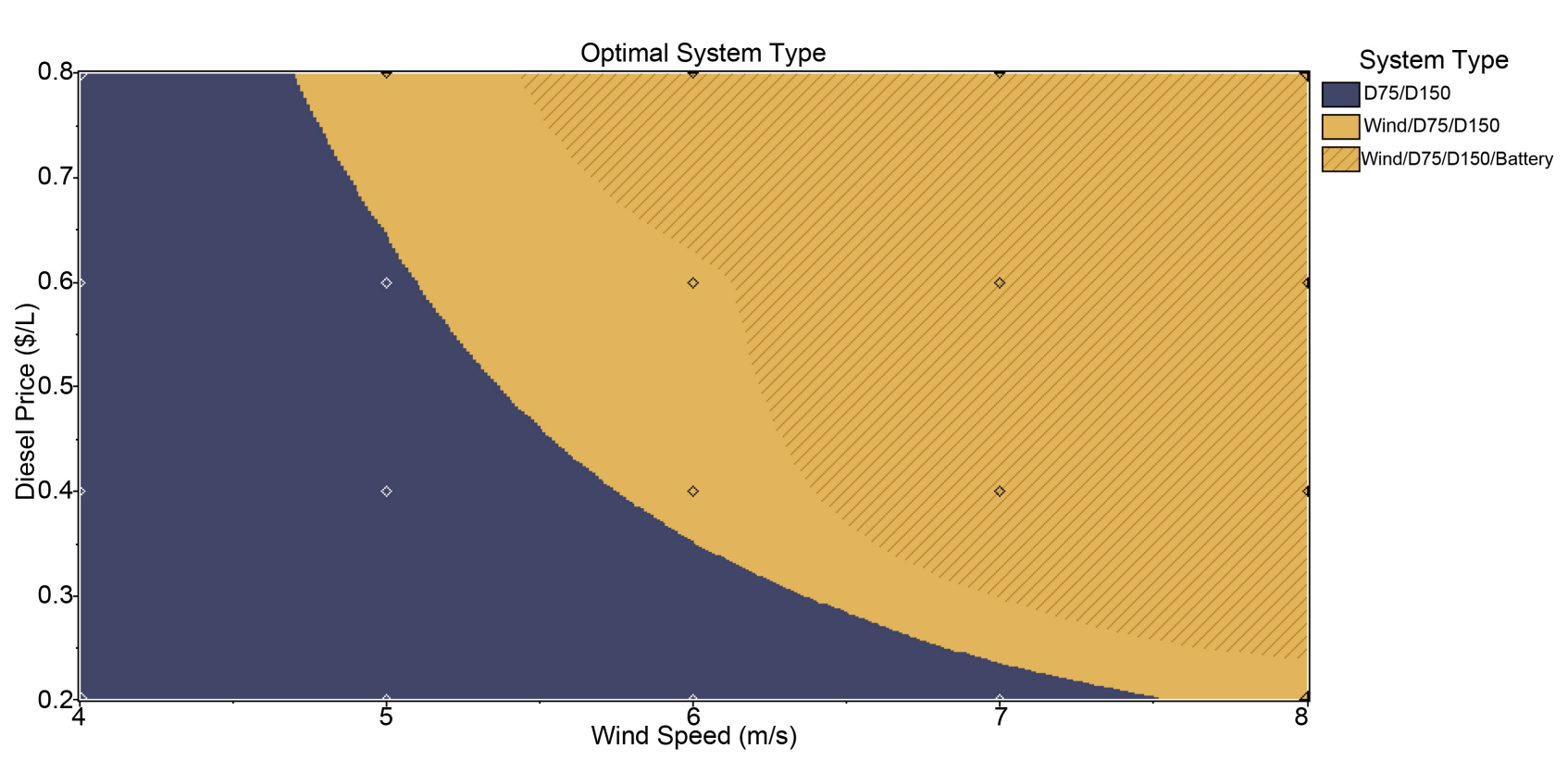

Figure 7. Optimization space for the wind diesel hybrid system under study.

of diesel generators. Likewise, the graph indicates that higher wind velocities enable solutions containing wind turbines.

Figure 8 shows the total NPC as a function of wind speed and oil price. One of the surfaces in this chart corresponds to systems composed only of diesel generators and the portion of this surface lying below the other forms the dark blue region of Figure 7 . The other surface corresponds to systems containing wind turbines and contributes to the yellow region of Figure 7.

These two surfaces intersect each other forming the curved line that appears in Figure 7. The optimization space is always formed by the parts of these surfaces with smaller values. It is interesting to note that the surface corresponding to diesel systems is flat, while the surface corresponding to wind turbine systems is a curved surface.

Homer adopts as the sole criterion the total NPC and the optimal systems are those with the lowest total NPC. Other criteria could obviously be adopted, such as the cost of energy. The next subsection presents the studied system analyzed with a new criterion, assuming the evaluation done with the terminal value as criterion for the optimal combinations.

\subsection{Results Based on Terminal Value Criterion}

The application of the method described above requires a sequence of calculations, partly described below but largely with results presented in a report available on the internet. The energy price must be defined in order to establish the cash flow that will be adopted in this work and the price that leads to a residual value equal to the initial investment will be chosen. Table 2 shows a cash flow obtained from the same data set that led to the results in Table 1 .

The second column of Table 2 shows a cash flow that was determined with energy price such that the residual value, appearing on the last line, is equal to 


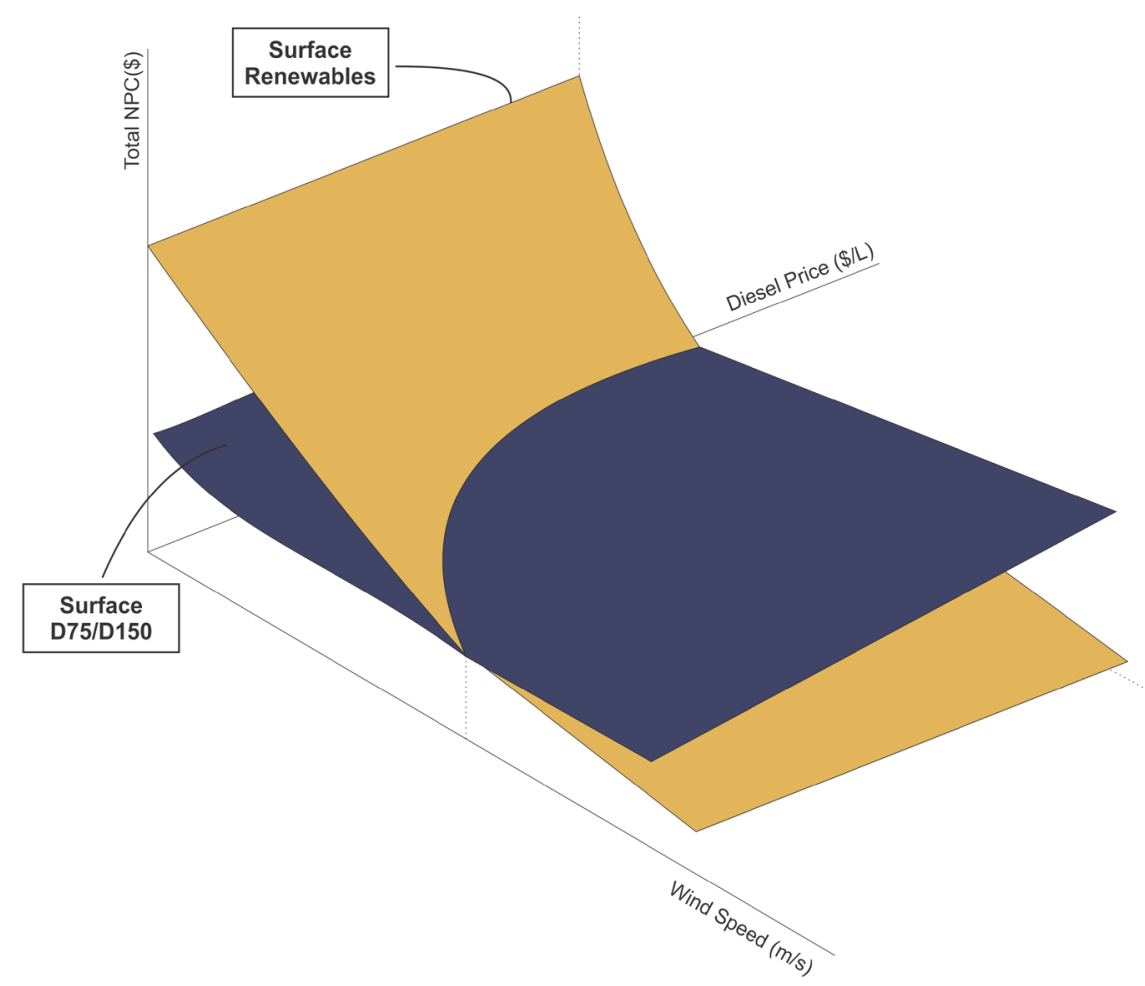

Figure 8. Total NPC as a function of wind speed and diesel price, showing the surfaces that make up the optimization space shown in Figure 7.

the initial capital. The following columns show this cash flow properly discounted considering discount rates of $5 \%, 10 \%$ and $15 \%$. This 25 year period, adopted for analysis for simulations with Homer, will be considered as the explicit period in this analysis.

Table 3 shows the main results of the analysis undertaken with the two energy prices. That is, with the analysis undertaken both from the data in Table 1 and the data in Table 2. The first two lines of Table 3 show the value obtained for the explicit period, discounted for time zero, and the value obtained for the terminal period.

The subsequent line shows the terminal value discounted at time zero. The next two lines then show first the sum of the values corresponding to the explicit period and the terminal period, and finally the ratio of the value of the explicit period and this sum. These three lines correspond to the terminal value determined without growth rates.

The next two sets of lines repeat these data for the terminal period presenting growth rates of $1 \%$ and $2 \%$. For the data corresponding to the terminal period without growth, the cash flows are all equal to the general term of the terminal value. For period with growth, the cash flows present increasing values from the terminal value. The terminal value will correspond to the year following the end of the explicit period.

Among all these cases, the system with energy price resulting in residual value equal to the initial capital and the discount rate of $5 \%$ is the only one that results 
Table 3. Discounted cash flows for discount rates equal to $5 \%, 10 \%$ and $15 \%$ for the cash flow of the wind diesel hybrid system simulated with Homer software. NPR is the net present result and TV is the terminal value. Data available in Ref. [17].

\begin{tabular}{ccccccc}
\hline & \multicolumn{3}{c}{ Residual Value equal to zero } & \multicolumn{3}{c}{ Residual Value ruqal to Initial Capital } \\
\cline { 2 - 7 } & $5 \%$ & $10 \%$ & $15 \%$ & $5 \%$ & $10 \%$ & $15 \%$ \\
\hline Explicit period & $-41,323.61$ & $-56,550.05$ & $-63,803.22$ & $14,995.79$ & $-20,278.20$ & $-37,972.48$ \\
Terminal value & 9750.24 & 9750.24 & 9750.24 & $13,746.24$ & $13,746.24$ & $13,746.24$ \\
Term value disc & $57,585.46$ & 8999.08 & 1974.60 & $81,186.01$ & $12,687.23$ & 2783.86 \\
NPR + TV & $16,261.85$ & $-47,550.97$ & $-61,828.63$ & $96,181.85$ & -7590.97 & $-35,188.63$ \\
NPR/(NPR + TV) & & & & 0.1559 & & \\
Term value disc & $71,981.82$ & 9998.98 & 2115.64 & $101,482.57$ & $14,096.92$ & 2982.70 \\
NPR + TV & $30,658.21$ & $-46,551.07$ & $-61,687.58$ & $116,478.36$ & -6181.28 & $-34,989.78$ \\
NPR/(NPR + TV) & & & & 0.1287 & & \\
Term value disc & $95,975.76$ & $11,248.85$ & 2278.38 & $135,310.09$ & $15,859.04$ & 3212.14 \\
NPR + TV & $54,652.15$ & $-45,301.20$ & $-61,524.84$ & $150,305.88$ & -4419.16 & $-34,760.34$ \\
NPR/(NPR + TV) & & & & 0.0998 & & \\
\hline
\end{tabular}

in all positive values. Considering the cash flow obtained with terminal period without growth, the repetition of these calculations for all the values of the sensitivity variables will allow to construct a new optimization space, established with criteria different from those adopted by Homer.

This new criterion should look for the highest value for the ratio between the net present result and the sum of net present result with the terminal value. Finding the systems that have the largest participation of the initial investment and lower operating costs is the objective of the proposed method, discarding systems based on non-renewable resources.

Figure 9 shows the ratio of $A$ to $B$ as a function of wind speed and diesel price. The optimization of space, in this case, should be obtained by the highest value among the values of the two surfaces. The interpretation of this figure is easier than the previous one, since the image seen from above shows the new optimization space. In this figure, the blue surface indicates the configurations with the two diesel generators and the yellow surface indicates the configurations with wind turbines.

Looking at this figure, the largest area corresponding to solutions including wind turbines is evident. In other words, the new criterion favors the selection of configurations with more wind power and consequently with greater participation of renewable energy conversion devices. In this way, the proposed method favors the selection of configurations with greater penetration of renewable energies.

\section{Conclusions}

This paper discussed the application of the terminal value to evaluate the feasibility of projects based on renewable resources. The application of this concept 


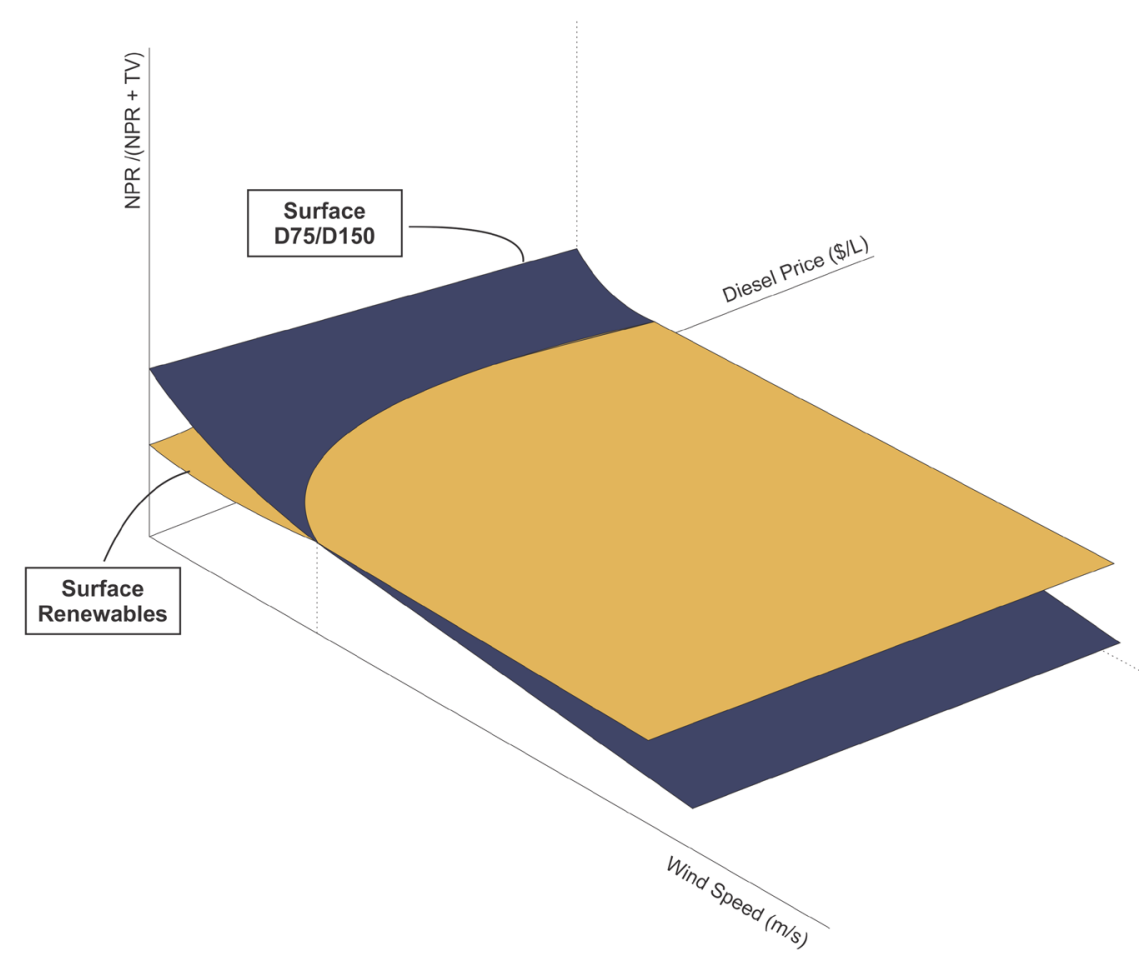

Figure 9. NPR/(NPR + VT) as a function of wind speed and diesel price, showing the surfaces that make up the optimization space that would be obtained with the terminal value as criterion.

allows the comparison, in a direct way and in a same basis, between systems based on renewable resources and systems based on fossil fuels. Finally, a method for feasibility analysis of hybrid energy systems is proposed and applied to a wind diesel hybrid system.

The criterion for hierarchizing power generation projects is the ratio between the value corresponding to the explicit period and the sum of the values corresponding to the explicit period and terminal period. Projects with higher values for this ratio will present higher initial investments and lower cash flows and, consequently, lower operating costs. Projects with higher operating costs will lead to lower values for this ratio.

The proposed method was applied to a wind diesel hybrid system simulated with the well-known software Homer and that later had its results recalculated according to the criterion presented in this article. The application of this criterion leads to a greater number of optimum solutions corresponding to solutions including wind turbines and, consequently, a greater penetration of renewable energies.

\section{Acknowledgements}

This work was developed as a part of research activities on renewable energy developed at the Instituto de Pesquisas Hidráulicas, Universidade Federal do Rio Grande do Sul. The authors acknowledge the support received by the institution. The second author acknowledges the financial support received from $\mathrm{CNPq}$ 
(proc. n. 309021/2014-6) for his research work.

\section{References}

[1] Lee, S.-C. and Shih, L.-H. (2010) Renewable Energy Policy Evaluation Using Real Option Model: The Case of Taiwan. Energy Economics, 32, 567-578. https://doi.org/10.1016/j.eneco.2010.04.010

[2] Akdag, S.A. and Güler, Ö. (2010) Evaluation of Wind Energy Investment Interest and Electricity Generation Cost Analysis for Turkey. Applied Energy, 87, 2574-2580. https://doi.org/10.1016/j.apenergy.2010.03.015

[3] Kaabeche, A., Belhamel, M. and Ibtiquen, R. (2011) Techno-Economic Valuation and Optimization of Integrated Photovoltaic/Wind Energy Conversion System. Solar Energy, 85, 2407-2420. https://doi.org/10.1016/j.solener.2011.06.032

[4] Lee, S.-C. (2011) Using Real Options Analysis for Highly Uncertain Technology investments: The case of wind energy technology. Renewable and Sustainable Energy Reviews 15, 4443-4450. https://doi.org/10.1016/j.rser.2011.07.107

[5] Martinez-Ceseña, E.A. and Mutale, J. (2011) Application of an Advanced Real Options Approach for Renewable Energy Generation Projects Planning. Renewable and Sustainable Energy Reviews, 15, 2087-2094.

https://doi.org/10.1016/j.rser.2011.01.016

[6] Boomasma, T.K., Meade, N. and Fleten, S.E. (2012) Renewable Energy Investments under Different Support Schemes: A Real Options Approach. European Journal of Operational Research, 220, 225-237. https://doi.org/10.1016/j.ejor.2012.01.017

[7] Kunbaroglu, G. and Madlener, R. (2012) Evaluation of Economically Optimal Retrofit Investment Options for Energy Savings in Buildings. Energy and Buildings, 49, 327-334. https://doi.org/10.1016/j.enbuild.2012.02.022

[8] Wüstenhagen, R. and Menighetti, E. (2012) Strategic Choices for Renewable Energy Investment: Conceptual Framework and Opportunities for Further Research. Energy Policy, 40, 1-10. https://doi.org/10.1016/j.enpol.2011.06.050

[9] Espinoza, R.D. and Rojo, J. (2015) Using DNPV for Valuing Investments in the Energy Sector: A Solar Project Case Study. Renewable Energy, 75, 44-49. https://doi.org/10.1016/j.renene.2014.09.011

[10] Espinoza, R.D. (2014) Separating Project Risk from the Time Value of Money: A Step toward Integration of Risk Management and Valuation of Infrastructure Investments. International Journal of Project Management, 32, 1056-1072. https://doi.org/10.1016/j.ijproman.2013.12.006

[11] REN21-Renewable Energy Policy Network for the 21st Century. Renewables 2016: Global Status Report, 2016.

[12] Twidell, J. and Weir, T. (2006) Renewable Energy Resources. Taylor \& Francis Group, London.

[13] Stevenson, W.J. (2001) Estatística aplicada à administração. Harbra, São Paulo.

[14] Downing, D. and Clark, J. (2002) Estatística aplicada. 2nd Edition, Saraiva, São Paulo.

[15] http://www.beluco.net/cases-adriano/Samples-WindDieselSystem.hmr

[16] Software HOMER, version 2.68 beta, The Micropower Optimization Model, Homer Energy. http://www.homerenergy.com

[17] Beluco, A. and Beluco, A. (2017) Terminal Value and Valuation Calculation Report for Feasibility Analysis of a Wind Diesel Hybrid System. Internal Report, Instituto de Pesquisas Hidráulicas, Universidade Federal do Rio Grande do Sul, 212 p. 
[18] Lambert, T., Gilman, P. and Lilienthal, P. (2006) Micropower System Modeling with Homer. Integration of Alternative Sources of Energy. John Wiley \& Sons, New York, 379-418. https://doi.org/10.1002/0471755621.ch15

[19] Lilienthal, P., Lambert, T.W. and Gilman, P. (2004) Computer Modeling of Renewable Power Systems. In: Cleveland, C.J., Encyclopedia of Energy, v. 1, 633-647, Elsevier, NREL Report CH-710-36771.

[20] Atlantic Orient Corporation, Wind Turbine Model AOC 15/50, Owner Manual. http://dl.owneriq.net/8/86af2010-6336-48e9-860d-9994ccb8135c.pdf

[21] Rolls Surrette Battery Company. Battery Model 6CS25P. Data Sheet. http://www.rollsbattery.com/wp-content/uploads/batteries/6CS25P.pdf 